\title{
Assessment of Epidemiological Determinants of COVID-19 Pandemic Related to Social and Economic Factors Globally
}

\author{
Mohammad Mahmudul Hassan ${ }^{1, *(D)}$, Md. Abul Kalam ${ }^{2}\left(\mathbb{D}\right.$, Shahanaj Shano ${ }^{3}$, \\ Md. Raihan Khan Nayem ${ }^{1}\left(\mathbb{D}\right.$, Md. Kaisar Rahman ${ }^{1,4}\left(\mathbb{D}\right.$, Shahneaz Ali Khan ${ }^{1}(\mathbb{D}$ and \\ Ariful Islam 4,5 \\ 1 Faculty of Veterinary Medicine, Chattogram Veterinary and Animal Sciences University, \\ Chattogram 4225, Bangladesh; raihannayem@gmail.com (M.R.K.N.); \\ kaisarrahman@ecohealthalliance.org (M.K.R.); shahneazbat@gmail.com (S.A.K.) \\ 2 Helen Keller International, Dhaka 1212, Bangladesh; a.kalam724@gmail.com \\ 3 Institute of Epidemiology, Disease Control and Research, Dhaka 1212, Bangladesh; \\ shahanajshano@gmail.com \\ 4 EcoHealth Alliance, New York, NY 10001, USA; arif@ecohealthalliance.org \\ 5 Centre for Integrative Ecology, School of Life and Environmental Sciences, Deakin University, \\ Geelong, VIC 3216, Australia \\ * Correspondence: miladhasan@yahoo.com
}

Received: 24 July 2020; Accepted: 28 August 2020; Published: 1 September 2020

\begin{abstract}
The COVID-19 pandemic has manifested more than a health crisis and has severely impacted on social, economic, and development crises in the world. The relationship of COVID-19 with countries' economic and other demographic statuses is an important criterion with which to assess the impact of this current outbreak. Based on available data from the online platform, we tested the hypotheses of a country's economic status, population density, the median age of the population, and urbanization pattern influence on the test, attack, case fatality, and recovery rates of COVID-19. We performed correlation and multivariate multinomial regression analysis with relative risk ratio (RRR) to test the hypotheses. The correlation analysis showed that population density and test rate had a significantly negative association $(\mathrm{r}=-0.2384, p=0.00)$. In contrast, the median age had a significant positive correlation with recovery rate $(\mathrm{r}=0.4654, p=0.00)$ and case fatality rate $(r=0.2847, p=0.00)$. The urban population rate had a positive significant correlation with recovery rate $(r=0.1610, p=0.04)$. Lower-middle-income countries had a negative significant correlation with case fatality rate $(\mathrm{r}=-0.3310, p=0.04)$. The multivariate multinomial logistic regression analysis revealed that low-income countries are more likely to have an increased risk of case fatality rate $(\mathrm{RRR}=0.986,95 \%$ Confidence Interval; $\mathrm{CI}=0.97-1.00, p<0.05)$ and recovery rate $(\mathrm{RRR}=0.967$, $95 \% \mathrm{CI}=0.95-0.98, p=0.00$ ). The lower-income countries are more likely to have a higher risk in case of attack rate $(\mathrm{RRR}=0.981,95 \% \mathrm{CI}=0.97-0.99, p=0.00)$ and recovery rate ( $\mathrm{RRR}=0.971$, $95 \% \mathrm{CI}=0.96-0.98, p=0.00$ ). Similarly, upper middle-income countries are more likely to have higher risk in case of attack rate $(\mathrm{RRR}=0.988,95 \% \mathrm{CI}=0.98-1.0, p=0.01)$ and recovery rate $(\mathrm{RRR}=0.978,95 \%$ $\mathrm{CI}=0.97-0.99, p=0.00$ ). The low- and lower-middle-income countries should invest more in health care services and implement adequate COVID-19 preventive measures to reduce the risk burden. We recommend a participatory, whole-of-government and whole-of-society approach for responding to the socio-economic challenges of COVID-19 and ensuring more resilient and robust health systems to safeguard against preventable deaths and poverty by improving public health outcomes.
\end{abstract}

Keywords: COVID-19; epidemiological determinants; population density; social and economic status 


\section{Introduction}

Severe acute respiratory syndrome coronavirus-2 (SARS-CoV-2), or COVID-19, has affected the advancement of humans' usual lifestyles, and now the whole world is fighting against an invisible enemy. In December 2019, a virus emerged in Wuhan, Hubei province, China, diffusing to more than 215 countries and regions with immense power of human-to-human transmission (She et al. 2020). Initially, the Chinese CDC (Center for Disease Control) isolated this novel virus belonging to the coronavirus family from a patient's lower respiratory tract, and then the World Health Organization (WHO) identified this virus as COVID-19 on 11 February 2020 (Surveillances 2020). Globally, as of 11:04 am CEST, 16 July 2020, there have been 13,338,364 confirmed cases of COVID-19, including 579,319 deaths officially reported by the WHO (WHO 2020). Still, the virus spillover point remains a mystery, as some studies have shown that it may originate from a seafood wholesale market (a local seafood and live animal market with different species including wildlife being sold) of Wuhan, China, and that the reservoir sources might be bats (Qiu 2020), which utilized an intermediate host, probably pangolins. Atypical pneumonia, fever, coughing, muscle soreness, and fatigue, were seen in critical cases and intensive care was often needed, as breathing difficulty was an expected outcome (Singhal 2020). Due to the lunar year celebration in China, the massive movement of people from and between the Asian region and other parts of the world increased the geographical spreading of this contagion immediately at the point of the outbreak (Boulos and Geraghty 2020). Higher mortality was seen in patients with comorbidities like cancer, diabetes, and high blood pressure, making the condition more critical (Zaki et al. 2020; Zhu et al. 2020). Rapidly, the disease has spread throughout the world, and now it has become a global pandemic with ongoing devastating effects continuing (Zheng 2020). Travel from the affected areas is one of the main causes of the spread of this disease between countries throughout the world (Gössling et al. 2020). The major social consequences of the pandemic are documented as prejudice and anxiety, which are sensitive to the current pandemic situation, and increased psychological distancing from the nations most affected (Karwowski et al. 2020; Sorokowski et al. 2020). Though the size and persistence of the economic impact is unanswerable, the global spread of COVID-19 has the potential to derail the world economy (Baldwin and Mauro 2020). There are potential direct consequences of COVID-19 on mental stress and indirect effects associated with psychiatric complications (Temsah et al. 2020; Vindegaard and Benros 2020).

However, there are limited research results on the global risk factors of COVID-19 transmission and patterns of spread (Wu et al. 2020; Bogoch et al. 2020; Chinazzi et al. 2020; Haider et al. 2020). Many countries of the globe are severely affected by COVID-19 with a higher number of cases and mortality, including the USA, Brazil, Russia, European countries (Spain, Italy, France, Germany, UK, etc.), Iran, and India. Overcrowded areas like schools, markets, public transport, and workplaces are the high-risk zones for transmission as it is a highly contagious infection (Rabi et al. 2020). Countries with high economic status, or modern cities, have chosen better workplaces for the people-aiming for more income, better quality of life, and better facilities. An urban area with high population density may be responsible for an epidemic situation. The pandemic situation of COVID-19 is aggravated by urbanization, as people fail to maintain social distance and so spread contamination. An urban area with high population density might be a risky place as more people come into contact with infected persons and increase the chance of contamination (Lindahl and Grace 2015). Moreover, critical care capacity is a problem in comparatively low- and lower-middle-income countries (Phua et al. 2020), and only a few hospitals have isolation capacity, which can provide intensive care with respiratory support. South Asia has an estimated 0.7-2.8 critical care beds per 100,000 population (Phua et al. 2020) and the number of beds is scarce in the lower- and middle-income countries compared to the more developed countries in the world. Furthermore, asymptomatic and early-stage infected persons can spread COVID-19 in the densely populated community. Older people are more prone to the disease and have a higher fatality rate than younger people, due to their clinical and immune responses (Nikolich-Zugich et al. 2020). The governments of different countries have implemented several steps to reduce the possibility of spreading the ongoing pandemic coronavirus. Social distancing, 
the lockdown of affected areas, restriction of public transport, working from home, and restriction of international flights were the crucial steps to prevent coronavirus spread.

Indeed, as the extensive spread of the COVID-19 virus around the globe has reached several million confirmed cases to date; the gradual concern will be not only our health but also our livelihoods. The demographic determinants in the population are the key to determine the contact patterns. Eventually, the pandemic will spread around the world, according to its nature, with implications for effective control measures in the foreseeable future from a government perspective (Ridenhour et al. 2018). Population density and the median age of individual populations are the most critical issues to be assessed to measure pandemics and their spread. The lower the population's median age in a community, the lower the disease incidence, even when pre-existing immunity levels in young individuals are low (Laskowski et al. 2011). Overall, the evolving nature of the pathogen, disease biology, and the demographic characteristics of the population are significant in identifying the type and intensity of public health intervention measures required for disease control (Choi 2012). Furthermore, the differential prevalence of predisposed health conditions and other types of health disparities increases uncertainty about how a novel virus would impact different countries with distinct mobility patterns, social interactions, and health characteristics. Based on available data from online sources, we tested the hypotheses of countries' economic status, population density, the median age of the population, and urbanization pattern influence on the test, attack, case fatality, and recovery rates of COVID-19.

\section{Materials and Methods}

\subsection{Data}

We extracted the total population of 2020 of the affected countries from the world population review (WPR) and the Worldometer database (Worldometer 2020). We extracted data on the total number of tests for COVID-19, new cases, total cases, total deaths, and total recovery from the WHO online database (Ritchie 2020). We analyzed data from the WHO coronavirus database from the beginning (January 2020) of the COVID-19 outbreak in China until 10 July 2020. Furthermore, we extracted the economic status of the individual country (based on GDP), population density per square kilometer, the median age of the population, and percentages of the people living in the urban area from the World Bank database (World Bank 2020). Primarily, we collected the data mentioned above from 204 countries and regions. Among them, we excluded some countries, as they did not disclose their data officially. We also excluded countries having populations less than 50,000. Finally, we included 163 countries' and regions' data in our analysis (Supplementary Table S1).

\subsection{Assessment of Test Rate, Attack Rate, Case Fatality Rate, and Recovery Rate}

We calculated the test rate, attack rate, case fatality rate, and recovery rate using the formula described (Kanchan et al. 2016) and given below:

$$
\text { Test Rate }=\frac{n \times 100}{N}
$$

Here, $n$ is the number of total tests among the susceptible population during the period and $N$ is the population at risk at the beginning of the period.

$$
\mathrm{AR}=\frac{n \mathrm{X} 100}{N}
$$

Here, AR is the attack rate, $n$ is the number of new cases among the population during the period and $N$ is the population at risk at the beginning of the period.

$$
\mathrm{CFR}=\frac{n \mathrm{X} 100}{N}
$$


Here, CFR is the case fatality rate, $n$ is the number of deaths due to the particular disease and $N$ is the total number of cases due to the same disease.

$$
\text { Recovery Rate }=\frac{n \mathrm{X} 100}{N}
$$

Here, $n$ is the number of recovered cases among the positively tested population during the study period and $N$ is the population at risk at the beginning.

To calculate the test rate, attack rate, case fatality rate, and recovery rate, we used data from open source and used the above formulae. We assessed the test rate for 100,000 population as a unit (per test), the attack rate for 100,000 population as a unit (per case), the case fatality rate for 100 cases (per death), and the recovery rate for 100 cases (per recovered case).

\subsection{Statistical Analysis}

The extracted data was analyzed using statistical data analysis software STATA/IC-13. We tested the hypotheses using correlations, and multivariate multinomial logistic regression with relative risk ratio analysis in the study. For the correlation analysis, we considered the country's economic status, population density rate, urbanization rate, and median age against its test rate, attack rate, case fatality rate, and recovery rate. Furthermore, we performed multivariate multinomial logistic regression analysis to understand the relationships between countries' economic statuses (explanatory variables) and the outcomes of the COVID-19 test rate, attack rate, case fatality rate, and recovery rate.

\section{Results}

\subsection{The Outcome of Correlation Analysis}

3.1.1. Population Density and COVID-19 Test Rate, Attack Rate, Case Fatality Rate, and Recovery Rate

The correlation of the population density of different countries with COVID-19 outcomes varied (Table 1). The analysis revealed that the correlation of population density and test rate had weak but significantly negative association $(\mathrm{r}=-0.2384, p=0.00)$. The analysis also revealed that the correlation of countries' population density with attack rate, case fatality rate, and recovery rate was insignificant negatively associated $(\mathrm{r}=-0.0175, p=0.82 ; \mathrm{r}=-0.0502, p=0.52$ and $\mathrm{r}=-0.0506, p=0.52$, respectively), demonstrates a weak relationship.

Table 1. Correlation analysis between population density rate and COVID-19 test, attack, fatality, and recovery rate.

\begin{tabular}{ccccc}
\hline Variables & $\begin{array}{c}\text { Population } \\
\text { Density (sq. km) }\end{array}$ & $\begin{array}{c}\text { Test Rate in One } \\
\text { Hundred Thousand }\end{array}$ & $\begin{array}{c}\text { Attack Rate in One } \\
\text { Hundred Thousand }\end{array}$ & Case Fatality Rate \\
\hline $\begin{array}{c}\text { Population density } \\
\text { (sq.km) }\end{array}$ & - & - & \\
\hline $\begin{array}{c}\text { Test rate in one } \\
\text { hundred thousand }\end{array}$ & $-0.2384 *$ & - & - \\
\hline $\begin{array}{c}\text { Attack rate in one } \\
\text { hundred thousand }\end{array}$ & -0.0175 & -0.1380 & 0.1208 & 0.0314 \\
\hline Case fatality rate & -0.0502 & 0.0893 & 0.0282 & - \\
\hline Recovery rate & -0.0506 & 0.0352 & $* p$ value $<0.05$. &
\end{tabular}

\subsubsection{Median Age and COVID-19 Test Rate, Attack Rate, Case Fatality Rate, and Recovery Rate}

Overall, COVID-19 outcomes had a significant positive relationship with the median age of the countries' populations (Table 2). Specifically, the analysis revealed that the median age of the populations of different countries was significantly positively associated with recovery rate $(\mathrm{r}=0.4654$, $p=0.00$ ), represents a moderate linear relationship (Figure 1) while the correlation with case fatality 
rate was weak but significantly positive $(\mathrm{r}=0.2847, p=0.00)$ (Figure 2$)$. On the other hand, the test rate and attack rate had not-significant positive correlations $(\mathrm{r}=0.0644, p=0.41$; and $\mathrm{r}=0.1250, p=0.11$, respectively), which demonstrates a weak linear association.

Table 2. Correlation analysis between median age and COVID-19 test, attack, fatality, and recovery rates.

\begin{tabular}{|c|c|c|c|c|c|}
\hline Variables & Median Age & $\begin{array}{c}\text { Test Rate in One } \\
\text { Hundred Thousand }\end{array}$ & $\begin{array}{l}\text { Attack Rate in One } \\
\text { Hundred Thousand }\end{array}$ & Case Fatality Rate & Recovery Rate \\
\hline Median age & - & & & & \\
\hline $\begin{array}{c}\text { Test rate in one } \\
\text { hundred thousand }\end{array}$ & 0.0644 & - & & & \\
\hline $\begin{array}{l}\text { Attack rate in one } \\
\text { hundred thousand }\end{array}$ & 0.1250 & -0.1380 & - & & \\
\hline Case fatality rate & 0.2847 & 0.0893 & 0.1208 & - & \\
\hline Recovery rate & $0.4654^{*}$ & 0.0352 & 0.0282 & 0.0314 & - \\
\hline
\end{tabular}

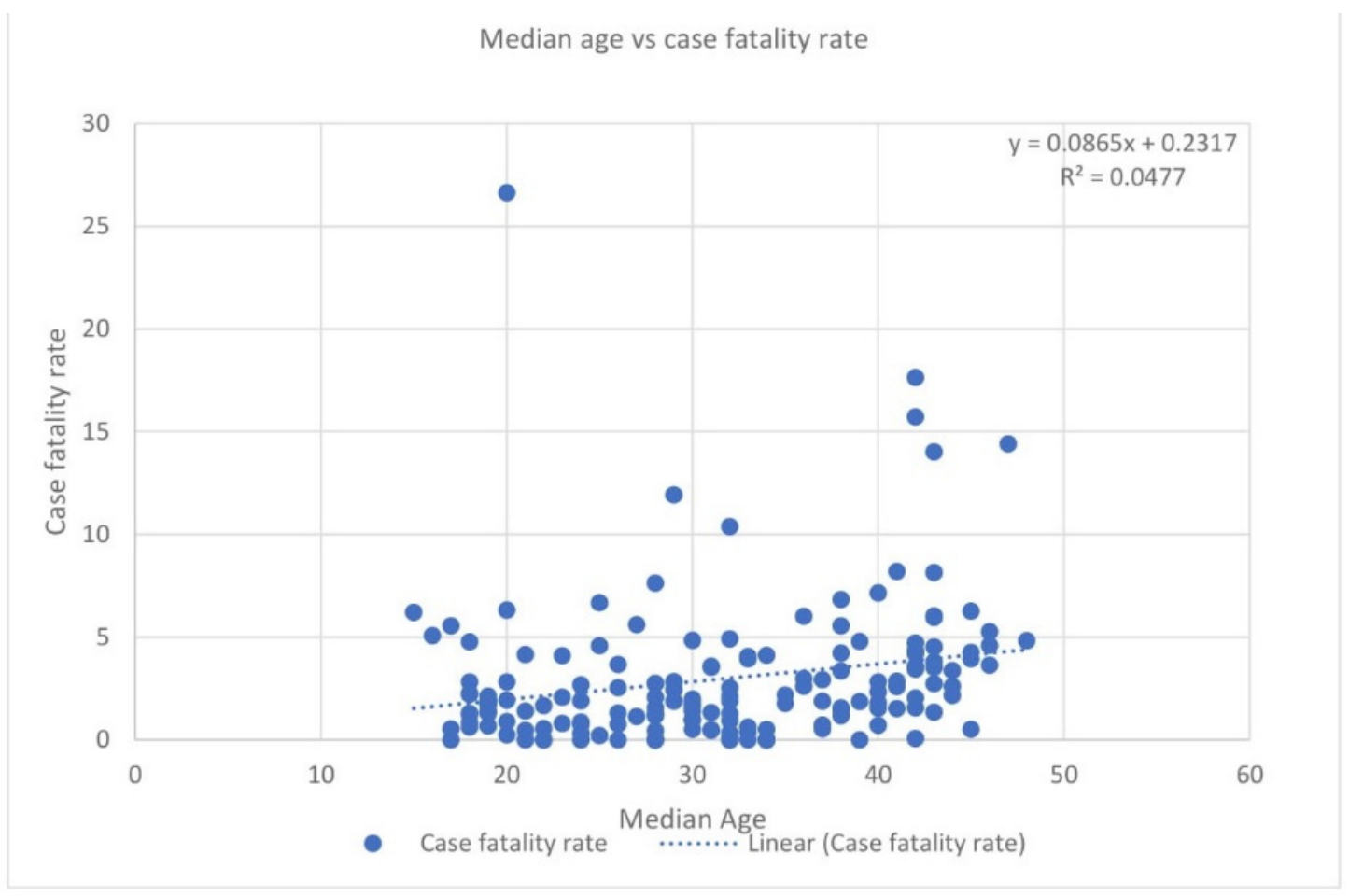

Figure 1. Correlation between median age and case fatality rate.

3.1.3. Urban Population Rate and COVID-19 Test Rate, Attack Rate, Case Fatality Rate, and Recovery Rate

In general, the urban population rate with COVID-19 outcomes had different correlations with different significance levels (Table 3). Precisely, the urban population rate had a positive significant correlation with recovery rate $(\mathrm{r}=0.1610, p=0.04)$, which demonstrates a weak linear relationship (Figure 3). In contrast, the correlations of the countries' urban population rate with test rate, attack rate, and case fatality rate were found to be positive $(r=-0.0290 ; r=0.0461 ;$ and $r=0.1477$, respectively) but the associations were not significant $(p=0.551 ; p=0.431$; and $p=0.164$, respectively), which depicts a weak linear relationship. 


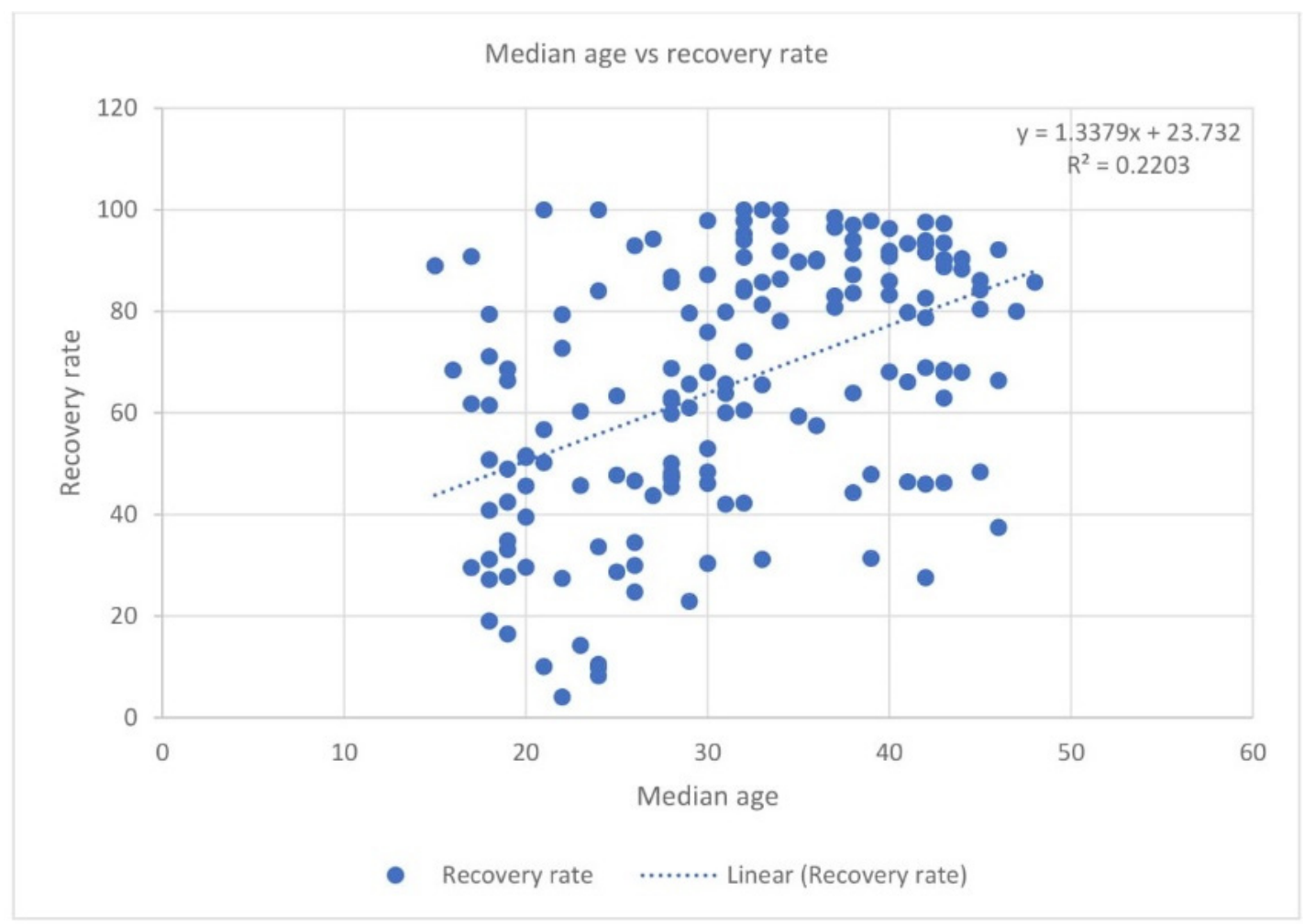

Figure 2. Correlation between median age and recovery rate.

Table 3. Correlation analysis between urban population rate and COVID-19 test, attack, fatality, and recovery rates.

\begin{tabular}{|c|c|c|c|c|c|}
\hline Variables & $\begin{array}{c}\text { Urban Population } \\
\text { Rate }\end{array}$ & $\begin{array}{l}\text { Test Rate in One } \\
\text { Hundred Thousand }\end{array}$ & $\begin{array}{l}\text { Attack Rate in One } \\
\text { Hundred Thousand }\end{array}$ & Case Fatality Rate & Recovery Rate \\
\hline $\begin{array}{l}\text { Urban population } \\
\text { rate }\end{array}$ & - & & & & \\
\hline $\begin{array}{c}\text { Test rate in one } \\
\text { hundred thousand }\end{array}$ & -0.0290 & - & & & \\
\hline $\begin{array}{l}\text { Attack rate in one } \\
\text { hundred thousand }\end{array}$ & 0.0461 & -0.1380 & - & & \\
\hline Case fatality rate & 0.1477 & 0.0893 & 0.1208 & - & \\
\hline Recovery rate & $0.1610 *$ & 0.0352 & 0.0282 & 0.0314 & - \\
\hline
\end{tabular}

3.1.4. Countries' Economic Status and COVID-19 Test Rate, Attack Rate, Case Fatality Rate, and Recovery Rate

In general, countries' economic status with COVID-19 outcomes had weak correlations with different significance levels (Table 4). Precisely, high-income countries had negative correlations with attack rate $(\mathrm{r}=-0.1455, p=0.29)$, and case fatality rate $(\mathrm{r}=-0.1164, p=0.40)$ but positive relationships with recovery rate $(r=0.1397, p=0.31)$. Similar trends were observed in the cases of lower-middle-income countries. Countries under this group had negative correlations with attack rate $(\mathrm{r}=-0.0602, p=0.72)$, case fatality rate $(\mathrm{r}=-0.3310, p=0.04)$, and recovery rate $(\mathrm{r}=-0.0260, p=0.88)$. However, the lower-income countries had positive correlations with attack rate $(\mathrm{r}=0.2577, p=0.27)$ and recovery rate $(\mathrm{r}=0.3027, p=0.19)$ but negative correlations with case fatality rate $(\mathrm{r}=-0.0009, p=1.0)$. Upper-middle-income countries had negative correlations with attack rate $(\mathrm{r}=-0.0607, p=0.68)$ and case fatality rate $(r=-0.0275, p=0.85)$ but positive correlations with recovery rate $(r=0.1275, p=0.38)$. 


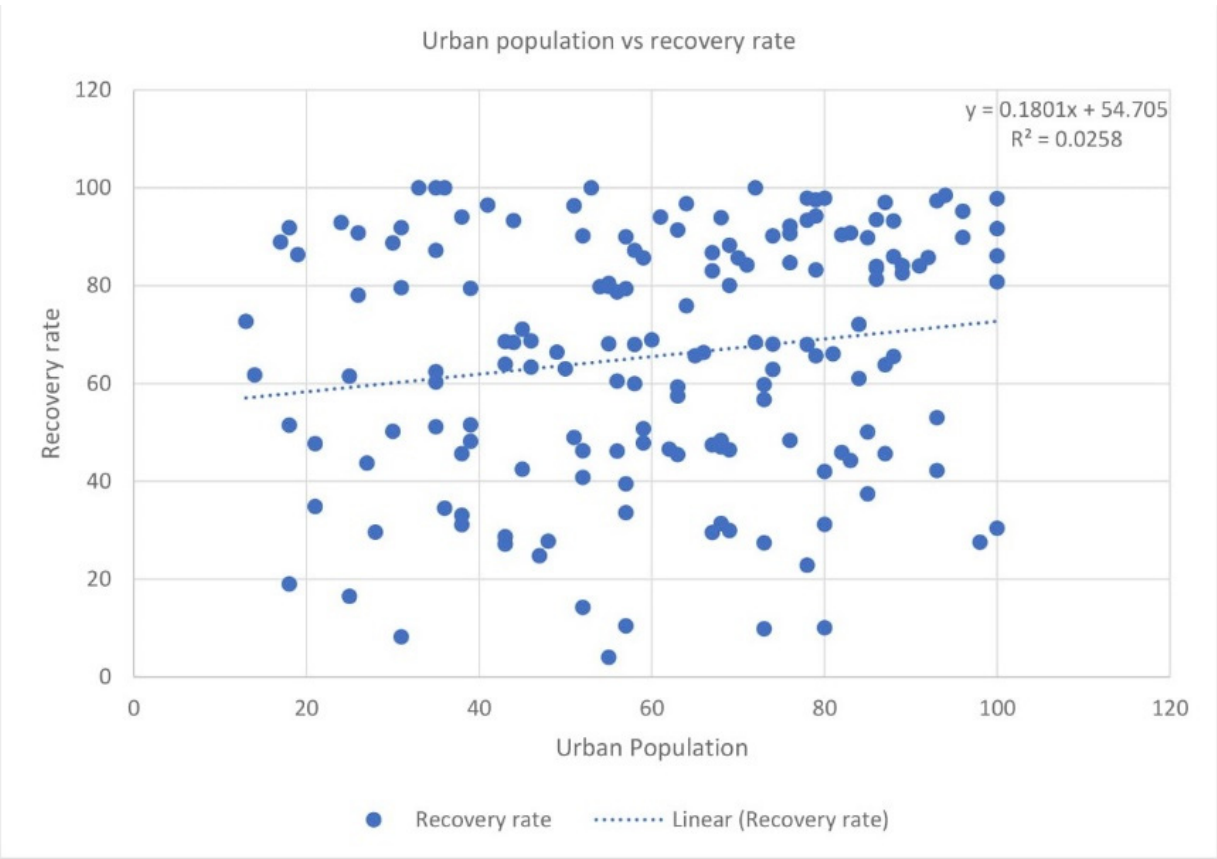

Figure 3. Correlation between urban population and recovery rate.

Table 4. Correlation analysis between countries' economic status (by group) and COVID-19 test, attack, fatality, and recovery rates.

\begin{tabular}{|c|c|c|c|c|}
\hline Variables & $\begin{array}{c}\text { Test Rate in One } \\
\text { Hundred Thousand }\end{array}$ & $\begin{array}{l}\text { Attack Rate in One } \\
\text { Hundred Thousand }\end{array}$ & Case Fatality Rate & Recovery Rate \\
\hline \multicolumn{5}{|c|}{ High-income countries } \\
\hline $\begin{array}{l}\text { Attack rate in one hundred } \\
\text { thousand }\end{array}$ & -0.1455 & - & & \\
\hline Recovery rate & 0.1397 & -0.2563 & -0.0275 & - \\
\hline \multicolumn{5}{|c|}{ Low-income countries } \\
\hline Test rate in one hundred thousand & - & & & \\
\hline $\begin{array}{l}\text { Attack rate in one hundred } \\
\text { thousand }\end{array}$ & 0.2577 & - & & \\
\hline Test rate in one hundred thousand & - & & & \\
\hline $\begin{array}{l}\text { Attack rate in one hundred } \\
\text { thousand }\end{array}$ & -0.0602 & - & & \\
\hline Case fatality rate & $-0.3310 *$ & 0.0052 & - & \\
\hline Recovery rate & -0.0260 & 0.0507 & -0.2838 & - \\
\hline \multicolumn{5}{|c|}{ Upper-middle-income countries } \\
\hline Test rate in one hundred thousand & - & & & \\
\hline $\begin{array}{l}\text { Attack rate in one hundred } \\
\text { thousand }\end{array}$ & -0.0607 & - & & \\
\hline
\end{tabular}




\subsection{Multinomial Logistic Regression Analysis of COVID-19 Epidemiological Determinants by Countries'} Economic Status

We performed multivariable multinomial logistic regression analysis to predict the economic status of different countries' influences on COVID-19 test rate, attack rate, case fatality rate, and recovery rate. Based on the World Bank's classifications, the economic statuses of different countries were categorized as "high income", "low income", "lower-middle income" and "upper-middle income". In the analysis, we compared the results of low income, lower-middle income, and upper-middle income with high-income countries. Therefore, we considered high-income countries as the base outcome. The results are given in Table 5.

Table 5. Multinomial logistic regression analysis on factors predicting the likelihood with relevant risk ratio.

\begin{tabular}{|c|c|c|c|c|}
\hline Economic Status & RRR & $* \mathrm{SE}$ & $p$-Value & $95 \% \mathrm{CI}$ \\
\hline High Income & \multicolumn{4}{|c|}{ (Base Outcome) } \\
\hline \multicolumn{5}{|c|}{ Low income } \\
\hline Test rate in one hundred thousand & 0.9969345 & 0.0062385 & 0.624 & $0.984782-1.009237$ \\
\hline $\begin{array}{c}\text { Attack rate in one hundred } \\
\text { thousand }\end{array}$ & 0.9986392 & 0.0066235 & 0.837 & $0.9857415-1.011706$ \\
\hline Case fatality rate & 0.9856455 & 0.0071833 & 0.047 & $0.9716666-0.9998254$ \\
\hline Recovery rate & 0.9669088 & 0.0072243 & 0.000 & $0.9528527-0.9811723$ \\
\hline \multicolumn{5}{|c|}{ Lower-middle income } \\
\hline Test rate in one hundred thousand & 0.9949272 & 0.0053644 & 0.346 & $0.9844685-1.005497$ \\
\hline $\begin{array}{l}\text { Attack rate in one hundred } \\
\text { thousand }\end{array}$ & 0.9811965 & 0.0055415 & 0.001 & $0.9703953-0.992118$ \\
\hline Case fatality rate & 0.9913426 & 0.0058717 & 0.142 & $0.9799008-1.002918$ \\
\hline Recovery rate & 0.971007 & 0.0058974 & 0.000 & $0.9595167-0.9826348$ \\
\hline \multicolumn{5}{|c|}{ Upper-middle income } \\
\hline Test rate in one hundred thousand & 0.9970542 & 0.0047419 & 0.535 & $0.9878034-1.006392$ \\
\hline $\begin{array}{l}\text { Attack rate in one hundred } \\
\text { thousand }\end{array}$ & 0.9880106 & 0.0048418 & 0.014 & $0.9785662-0.9975461$ \\
\hline Case fatality rate & 0.9944589 & 0.0050761 & 0.276 & $0.9845595-1.004458$ \\
\hline Recovery rate & 0.9782491 & 0.0052234 & 0.000 & $0.9680647-0.9885406$ \\
\hline
\end{tabular}

The multivariable multinomial logistic regression analysis revealed, the relative risk ratio (RRR) for 'case fatality rate' indicates that the 'low-income countries' have an 0.986 times increased risk compared to higher-income countries, which is a significant predictor ( $\mathrm{SE}=0.0071,95 \% \mathrm{CI}=0.97-1.00$, $p<0.05)$, while the RRR for 'recovery rate' indicates that the low-income countries have 0.967 times increased risk, which is also a significant predictor ( $\mathrm{SE}=0.0072,95 \% \mathrm{CI}=0.95-0.98, p=0.00$ ). In the case of 'test rate' and 'attack rate' low-income countries have an increased but insignificant risk compared to high-income countries $(\mathrm{RRR}=0.997, \mathrm{SE}=0.0062,95 \% \mathrm{CI}=0.98-1.01, p=0.62$; and $\mathrm{RRR}=0.999$, $\mathrm{SE}=0.0066,95 \% \mathrm{CI}=0.99-1.01, p=0.84$, respectively).

On the other hand, the RRR for 'attack rate' indicates that the lower-middle-income countries have an 0.981 times increased risk compared to that of higher-income countries, which is a significant predictor $(\mathrm{SE}=0.0054,95 \% \mathrm{CI}=0.97-0.99, p=0.00)$. In the case of 'recovery rate' it is a 0.971 times increased risk, which is a significant predictor $(\mathrm{SE}=0.0059,95 \% \mathrm{CI}=0.96-0.98, p=0.00)$. The analysis also revealed that, 'test rate' and 'case fatality rate' have an increased but insignificant risk compared 
to high-income countries $(\mathrm{RRR}=0.994, \mathrm{SE}=0.0053,95 \% \mathrm{CI}=0.98-1.01, p=0.35$; and $\mathrm{RRR}=0.991$, $\mathrm{SE}=0.0059,95 \% \mathrm{CI}=0.98-1.00, p=0.14$, respectively).

A similar pattern was observed in upper-middle-income countries. The RRR for 'attack rate' indicates that the upper-middle-income countries have an 0.988 times increased risk compared to that of higher income countries, which is a significant predictor ( $\mathrm{SE}=0.0048,95 \% \mathrm{CI}=0.98-1.0, p=0.01$ ). In the case of 'recovery rate' it has an 0.978 times increased risk, which is a significant predictor (SE $=0.0052$, $95 \% \mathrm{CI}=0.97-0.99, p=0.00$ ). Furthermore it was also found that 'test rate' and 'case fatality rate' have an increased but insignificant risk compared to high-income countries ( $R R R=0.997, \mathrm{SE}=0.0047,95 \%$ $\mathrm{CI}=0.99-1.01, p=0.54$; and $\mathrm{RRR}=0.994, \mathrm{SE}=0.0051,95 \% \mathrm{CI}=0.98-1.00, p=0.28$, respectively).

\section{Discussion}

4.1. Possible Effects of Social and Economic Factors on COVID-19 Test Rate, Attack Rate, Case Fatality Rate, and Recovery Rate

We have analyzed the impact of population density of the countries being affected by COVID-19 by examining the correlations with defined selected outcomes in this study. However, population density produces a positive impact, although it had an insignificant relationship with the COVID-19 test rate and case fatality rate, while negative but insignificant relationships were found with attack rate and recovery rate. The outcomes of this statistical model demonstrated that the population density of the particular countries does not have any positive significant relations with COVID-19 outcomes. In infectious disease epidemiology, population density is the communication mode likely to follow an initial sub-linear density-dependent form until the saturation of transmission rate evolutions (Hu et al. 2013). The proven principles indicate that an epidemic of transmissible disease spreads more rapidly and intensely in densely populated areas (Tarwater and Martin 2001) than in lightly populated areas because of the lower chances of interpersonal contacts or mixing in the lower-population-density countries or areas (Rocklöv and Sjödin 2020). These opposing findings might be because COVID-19 is currently anticipated to transmit only through person-to-person contact, and contact with contaminated surfaces might not be significant. Other means of virus spread need to be explored. Travelers, social events like marriage ceremonies, birthdays, etc., and different religious congregations might be some other factors increasing the disease burden even in places where population density is not too high. The rapidly growing populations force the creation of megacities in China and India, and produce fast-track international connectivity seeking the importance of more research on this aspect of COVID-19 impact in the densely populated countries. The mega countries like China, India, Brazil, could be the places where the pandemic is posing significant public health threats. A positive relationship between mortality rates and population densities in the USA from the perspective of influenza pandemics has been recognized (Chandra et al. 2013). Once cities are introduced into the equation, normalizing the mortality rates of the cities with those of the states also showed a positive relationship with population density. The opposite scenario also identified a link between population density and mortality for the 1918 pandemic; in rural areas of Wales and England (Chowell et al. 2008), the low population density was positively associated with mortality. On a larger country scale, however, they found no connection between population density or residential crowding and mortality or transmissibility.

The median age has significant positive relations with attack rate, case fatality rate, and recovery rate while insignificant positive association has been observed in the case of test rates. The median age positively influences the COVID-19 attack rate, recovery rate, and case fatality rate. Previous research indicated that the increasing median age had increased the chance of infection (Velavan and Meyer 2020) and death, as recent findings suggested patients with age $\geq 60$ years are at higher risk (Verity et al. 2020) than children-who might be less likely to become infected or if so, may show milder symptoms or even asymptomatic infection ( $\mathrm{Li}$ et al. 2020). In this globalization of the one-village concept, the population demographic feature being changed through an increase in life expectancy and decreasing fertility led to the establishment of older people living in smaller households. The drivers of these demographics include public health improvement and social and economic transformation associated with the 
growth of urbanization (Whiting and Unwin 2009). Similar trends are occurring, at differing rates and dimensions, among the less-developed countries of the world. Understanding how changes in the demographic structure of a population affect disease transmission is a necessity step towards the design of more effective strategies for disease control. However, the case fatality rate of COVID-19 infections has been lower (12 March 2020, 6.22\% versus 23 March 2020, 9.26\%) (Khafaie and Rahim 2020) than recently occurred other outbreaks; as it was $9.6 \%$ in the SARS-CoV outbreak (Qiu et al. 2018) and 34.4\% in the MERS-CoV outbreak (Willman et al. 2019).

The ratio of the urban population has a positive significant relation towards recovery rate. On the other hand, the relation with test rates was found to be negative but insignificant, while association with case fatality rate and attack rate was found to be positive but insignificant. That means that urban people are more likely to recover from COVID-19. Urban areas are considered as the centers of any country as they provide high-quality public services along with improved health care facilities. Both government and private sectors invest in and provide improved health care by establishing complicated health infrastructure to attract people to become inhabitants in the urban areas. As a result, health and health-service provisions are improved and more intensive in urban areas than in rural areas. Urbanization presents the emergence of zoonotic diseases as the rapid intensification of agriculture, socioeconomic change, and ecological fragmentation, which can have profound impacts on the epidemiology of infectious disease (Hassell et al. 2017). Urban planning and appropriate surveillance system can be powerful tools to improve global health and decrease the burden, especially of highly transmissible diseases (Neiderud 2015). However, the shift of populations from rural areas to the urban landscape, poses the risk of the concentration of a succession of epidemics and pandemics in cities becoming stronger (Avetisyan 2020). Urban activities provide a space for people to come together. This goes against the rules of social distancing. The other factor within a city in which urban poor people live is the many public amenities, such as toilets and water supply. Avoiding crowding in this situation becomes almost impossible. The consequence of this city deficit is borne out by a vast number of cases among slums and the urban poor. Cities also attract travelers and tourists from across the world. Throughout the pandemic, they have especially crafted their policies and city services to assist and facilitate these visitors. One of the reasons why European countries suffered so badly was due to the ingress of Chinese and other tourists that promoted a more substantial and quicker spread of the virus.

Gross domestic product (GDP) is the indicator for the status of the individual country, and the World Bank has categorized the countries as high-income, upper-middle income, lower-middle-income, and low-income (World Bank 2020). Low- and middle-income countries (LMICs) are less likely to have an increased recovery rate, and attack rate compared to high-income countries. This might be due to the lack of proper healthcare facilities, financial status, lack of awareness, lack of human resources, and expertise in LMICs (Khadka et al. 2020). Usually, the healthcare sector receives little attention from the international public health community; these problems are not restricted to high-income countries but are becoming increasingly crucial in middle-income and, to a lesser extent, some low-income countries (Weatherall et al. 2006). Lower-middle-income and upper-middle-income countries are less likely to have an increased recovery rate compared to high-income countries. Individuals in low- and middle-income countries have to fight mainly against infectious and contagious diseases, while in the high-income countries, battles are mostly against lifestyle diseases (Singh and Singh 2008) as the healthcare system provides significant facilities.

Person-to-person contact, using public transport during travel, and exposure to public gatherings and social and religious events are the primary sources of spreading this virus massively (Zheng et al. 2020). Therefore, in keeping with the World Health Organization's guidelines, countries are taking different initiatives to stop the spread. Maintaining social distancing, isolation, quarantine, and lockdown are the key measures. Countries have failed to control the extent of COVID-19 due to people's attitudes of denial and misunderstanding of social distancing for the control of an epidemic (Maharaj and Kleczkowski 2012; Fast et al. 2015). However, if we consider the recent 
trend of COVID-19 attack, recovery, and death rates, then it can be said that these measures fail to stop the spreading virus due to not considering the economic and demographic factors. In this context, our study offers some key factors, which have a positive correlation with COVID-19. These factors should be considered in designing an effective spread-control mechanism. The trends on the test, attack, case fatality, and recovery rates may change after this time. In this regard, this study may not represent the whole COVID-19 scenario.

\subsection{Limitations of the Study}

Nevertheless, we must acknowledge the limitations of our present research work. Firstly, we used data until 10 July 2020 and the status might have changed over the intervening time. Besides which, asymptomatic cases of COVID-19 were not considered in the study since the WHO, or other authentic organization or any governmental authority, did not report the number of asymptomatic cases of COVID-19. Up to now, globally, nobody has known the accurate data of asymptomatic cases of COVID-19. Secondly, the relevant data of epidemiological, socio-demographic, and economic factors were collected from publicly available sources including the WHO, World Bank, Worldometer, etc., which may have some limitations in terms of accuracy and precision. Thirdly, heterogeneity of the diagnosis, and data reporting among the different countries were not considered in this study. This might affect the deviation of the associations between social and economic factors and COVID-19 spread. Furthermore, we need to consider the up-to-date COVID-19 test rate, attack rate, case fatality rate, and recovery rate, and include missing data on social and economic factors during the ongoing COVID-19 pandemic. Finally, other factors such as temperature, humidity, social distancing, number of tourists, and compliance with preventive measures also contribute to the number of confirmed cases of COVID-19 (Xie and Zhu 2020; Sorokowska et al. 2017; Qiu et al. 2020; Lieberoth et al. 2020; Hassan et al. 2020). These factors were not considered in our analysis.

\section{Conclusions}

By analyzing the COVID-19 data, economic status, and population data of 163 countries, we found that economic status, the median age of the population, and urban population ratio had a significant influence on COVID-19 attack rate, case fatality rate, and recovery rate. We recommend considering the economic and demographic factors as a whole-society approach to tackle the pandemic and maintain livelihoods. The low- and lower-middle-income countries should invest more in healthcare services to lower the case fatality rate and increase test and recovery rates as part of pandemic preparation for situations like COVID-19. We strongly recommend the adoption of this strategy into nations' health and pandemic preparedness policies.

Supplementary Materials: The following are available online at http://www.mdpi.com/1911-8074/13/9/194/s1, Table S1. Metadata of global populations per country along with sociodemographic, economic status and other factors related to COVID-19 until 10 July 2020.

Author Contributions: Conceptualization, M.M.H., M.A.K., and A.I.; methodology, M.M.H., and M.A.K.; software, M.M.H., and M.A.K.; validation, M.A.K., S.A.K., and A.I.; formal analysis, M.M.H., M.A.K., M.K.R., and A.I.; investigation, M.M.H. and M.A.K.; data curation, M.M.H, M.A.K., M.K.R., and M.R.K.N.; writing-original draft preparation, M.M.H, and M.A.K.; writing—review and editing, M.M.H., A.K., S.S., M.K.R., S.A.K., and A.I.; visualization, M.M.H., and M.A.K.; supervision, M.M.H.; project administration, M.M.H., and A.I. All authors have read and agreed to the published version of the manuscript.

Funding: This research was funded by Bangladesh Bureau of Educational Information and Statistics (grant number SD-2019967).

Acknowledgments: We acknowledge the Department of Health Services, of each country of the globe for publicly sharing COVID-19 outbreak related data. We thank Chattogram Veterinary and Animal Sciences University (CVASU) and EcoHealth Alliance for continuous support to our research team.

Conflicts of Interest: The authors declare no conflict of interest.

Ethical Statements: Not required as we used open sources data for preparation of manuscript. 


\section{References}

Avetisyan, Sergey. 2020. Coronavirus and Urbanisation: Do Pandemics Are Anti-Urban? Available online: http://dx.doi.org/10.2139/ssrn.3584395 (accessed on 31 August 2020).

Baldwin, Richard, and Beatrice Weder di Mauro. 2020. Economics in the Time of Covid-19. London: CEPR Press. Bogoch, Isaac I., Alexander Watts, Andrea Thomas-Bachli, Carmen Huber, Moritz UG Kraemer, and Kamran Khan. 2020. Potential for Global Spread of a Novel Coronavirus from China. Journal of Travel Medicine 27: taaa011. [CrossRef] [PubMed]

Boulos, Maged N. Kamel, and Estella M. Geraghty. 2020. Geographical Tracking and Mapping of Coronavirus Disease Covid-19/Severe Acute Respiratory Syndrome Coronavirus 2 (Sars-Cov-2) Epidemic and Associated Events around the World: How 21st Century Gis Technologies Are Supporting the Global Fight against Outbreaks and Epidemics. International Journal of Health Geographics 19: 8.

Chandra, Siddharth, Eva Kassens-Noor, Goran Kuljanin, and Joshua Vertalka. 2013. A Geographic Analysis of Population Density Thresholds in the Influenza Pandemic of 1918-19. International Journal of Health Geographics 12: 9. [CrossRef] [PubMed]

Chinazzi, Matteo, Jessica T. Davis, Corrado Gioannini, Maria Litvinova, A. Pastore y Piontti, Luca Rossi, Xinyue Xiong, M. Elizabeth Halloran, I. M. Longini, and Alessandro Vespignani. 2020. Preliminary Assessment of the International Spreading Risk Associated with the 2019 Novel Coronavirus (2019-Ncov) Outbreak in Wuhan City. Boston: Laboratory for the Modeling of Biological and Socio-Technical Systems.

Choi, Bernard C. K. 2012. The Past, Present, and Future of Public Health Surveillance. Scientifica 2012: 875253. [CrossRef]

Chowell, Gerardo, Luis M. A. Bettencourt, Niall Johnson, Wladimir J. Alonso, and Cecile Viboud. 2008. The 1918-1919 Influenza Pandemic in England and Wales: Spatial Patterns in Transmissibility and Mortality Impact. Proceedings of the Royal Society B: Biological Sciences 275: 501-9. [CrossRef]

Fast, Shannon M., Marta C. Gonzalez, and Natasha Markuzon. 2015. Cost-Effective Control of Infectious Disease Outbreaks Accounting for Societal Reaction. PLoS ONE 10: e0136059. [CrossRef] [PubMed]

Gössling, Stefan, Daniel Scott, and C. Michael Hall. 2020. Pandemics, Tourism and Global Change: A Rapid Assessment of Covid-19. Journal of Sustainable Tourism, 1-20. [CrossRef]

Haider, Najmul, Alexei Yavlinsky, David Simons, Abdinasir Yusuf Osman, Francine Ntoumi, Alimuddin Zumla, and Richard Kock. 2020. Passengers' Destinations from China: Low Risk of Novel Coronavirus (2019-Ncov) Transmission into Africa and South America. Epidemiology and Infection 148: e41. [CrossRef]

Hassan, Mohammad M., Mohamed E. El Zowalaty, Shahneaz A. Khan, Ariful Islam, Md Raihan K. Nayem, and Josef D. Järhult. 2020. Role of Environmental Temperature on the Attack Rate and Case Fatality Rate of Coronavirus Disease 2019 (Covid-19) Pandemic. Infection Ecology \& Epidemiology 10: 1792620.

Hassell, James M., Michael Begon, Melissa J. Ward, and Eric M. Fèvre. 2017. Urbanization and Disease Emergence: Dynamics at the Wildlife-Livestock-Human Interface. Trends in Ecology E Evolution 32: 55-67.

$\mathrm{Hu}$, Hao, Karima Nigmatulina, and Philip Eckhoff. 2013. The Scaling of Contact Rates with Population Density for the Infectious Disease Models. Mathematical Biosciences 244: 125-34. [CrossRef] [PubMed]

Kanchan, T., N. Kumar, and B. Unnikrishnan. 2016. Mortality: Statistics. In Encyclopedia of Forensic and Legal Medicine, 2nd ed. Edited by Jason Payne-James and Roger W. Byard. Oxford: Elsevier, pp. 572-77.

Karwowski, Maciej, Marta Kowal, Agata Groyecka, Michał Białek, Izabela Lebuda, Agnieszka Sorokowska, and Piotr Sorokowski. 2020. When in Danger, Turn Right: Does Covid-19 Threat Promote Social Conservatism and Right-Wing Presidential Candidates. Human Ethology. [CrossRef]

Khadka, Sitaram, Furqan K. Hashmi, and Muhammad Usman. 2020. Preventing Covid-19 in Low-and Middle-Income Countries. Drugs \& Therapy Perspectives, 1-3. [CrossRef]

Khafaie, Morteza Abdullatif, and Fakher Rahim. 2020. Cross-Country Comparison of Case Fatality Rates of Covid-19/Sars-Cov-2. Osong Public Health and Research Perspectives 11: 74. [CrossRef] [PubMed]

Laskowski, Marek, Luiz C. Mostaço-Guidolin, Amy L. Greer, Jianhong Wu, and Seyed M. Moghadas. 2011. The Impact of Demographic Variables on Disease Spread: Influenza in Remote Communities. Scientific Reports 1: 1-7. [CrossRef]

Li, Qun, Xuhua Guan, Peng Wu, Xiaoye Wang, Lei Zhou, Yeqing Tong, Ruiqi Ren, Kathy S. M. Leung, Eric H. Y. Lau, and Jessica Y. Wong. 2020. Early Transmission Dynamics in Wuhan, China, of Novel Coronavirus-Infected Pneumonia. New England Journal of Medicine 382: 1199-207. [CrossRef] 
Lieberoth, Andreas, Shiang-Yi Lin, Sabrina Stöckli, Hyemin Han, Marta Kowal, Stavroula Chrona, and Gelpí Rebekah. 2020. Stress and Worry in the 2020 Coronavirus Pandemic: Relationships to Trust and Compliance with Preventive Measures across $45^{*}$ Countries. Royal Society Open Science. Available online: https://osf.io/vz73d/ (accessed on 31 August 2020).

Lindahl, Johanna F., and Delia Grace. 2015. The Consequences of Human Actions on Risks for Infectious Diseases: A Review. Infection Ecology E Epidemiology 5: 30048.

Maharaj, Savi, and Adam Kleczkowski. 2012. Controlling Epidemic Spread by Social Distancing: Do It Well or Not at All. BMC Public Health 12: 679. [CrossRef]

Neiderud, Carl-Johan. 2015. How Urbanization Affects the Epidemiology of Emerging Infectious Diseases. Infection Ecology \& Epidemiology 5: 27060.

Nikolich-Zugich, Janko, Kenneth S. Knox, Carlos Tafich Rios, Bhupinder Natt, Deepta Bhattacharya, and Mindy J. Fain. 2020. Sars-Cov-2 and Covid-19 in Older Adults: What We May Expect Regarding Pathogenesis, Immune Responses, and Outcomes. GeroScience, 1-10. [CrossRef]

Phua, Jason, Mohammad Omar Faruq, Atul P. Kulkarni, Ike Sri Redjeki, Khamsay Detleuxay, Naranpurev Mendsaikhan, Kyi Kyi Sann, Babu Raja Shrestha, Madiha Hashmi, and Jose Emmanuel M. Palo. 2020. Critical Care Bed Capacity in Asian Countries and Regions. Critical Care Medicine. [CrossRef] [PubMed]

Qiu, Jane. 2020. How China's 'Bat Woman' hunted Down Viruses from Sars to the New Coronavirus. Scientific American 322: 24-32.

Qiu, Wuqi, Cordia Chu, Ayan Mao, and Jing Wu. 2018. The Impacts on Health, Society, and Economy of Sars and H7n9 Outbreaks in China: A Case Comparison Study. Journal of Environmental and Public Health 2018: 2710185. [CrossRef] [PubMed]

Qiu, Richard T. R., Jinah Park, Shina Li, and Haiyan Song. 2020. Social Costs of Tourism During the Covid-19 Pandemic. Annals of Tourism Research 84: 102994. [CrossRef]

Rabi, Firas A., Mazhar S. Al Zoubi, Ghena A. Kasasbeh, Dunia M. Salameh, and Amjad D. Al-Nasser. 2020. Sars-Cov-2 and Coronavirus Disease 2019: What We Know So Far. Pathogens 9: 231. [CrossRef]

Ridenhour, Benjamin, Jessica M. Kowalik, and David K. Shay. 2018. Unraveling R 0: Considerations for Public Health Applications. American Journal of Public Health 108: S445-S454. [CrossRef]

Ritchie, Hannah. 2020. Coronavirus Source Data. Our World in Data. Available online: https://ourworldindata.org/ coronavirus-source-data (accessed on 31 August 2020).

Rocklöv, Joacim, and Henrik Sjödin. 2020. High Population Densities Catalyse the Spread of Covid-19. Journal of Travel Medicine 27: taaa038.

She, Jun, Jinjun Jiang, Ling Ye, Lijuan Hu, Chunxue Bai, and Yuanlin Song. 2020. 2019 Novel Coronavirus of Pneumonia in Wuhan, China: Emerging Attack and Management Strategies. Clinical and Translational Medicine 9: 1-7. [CrossRef]

Singh, Ajai R., and Shakuntala A. Singh. 2008. Diseases of Poverty and Lifestyle, Well-Being and Human Development. Mens Sana Monographs 6: 187. [CrossRef]

Singhal, Tanu. 2020. A Review of Coronavirus Disease-2019 (Covid-19). The Indian Journal of Pediatrics, 1-6. [CrossRef] [PubMed]

Sorokowska, Agnieszka, Piotr Sorokowski, Peter Hilpert, Katarzyna Cantarero, Tomasz Frackowiak, Khodabakhsh Ahmadi, Ahmad M. Alghraibeh, Richmond Aryeetey, Anna Bertoni, and Karim Bettache. 2017. Preferred Interpersonal Distances: A Global Comparison. Journal of Cross-Cultural Psychology 48: 577-92. [CrossRef]

Sorokowski, Piotr, Agata Groyecka, Marta Kowal, Agnieszka Sorokowska, Michał Białek, Izabela Lebuda, Małgorzata Dobrowolska, Przemysław Zdybek, and Maciej Karwowski. 2020. Can Information About Pandemics Increase Negative Attitudes toward Foreign Groups? A Case of Covid-19 Outbreak. Sustainability 12: 4912. [CrossRef]

Surveillances, Vital. 2020. The Epidemiological Characteristics of an Outbreak of 2019 Novel Coronavirus Diseases (Covid-19)—China, 2020. China CDC Weekly 2: 113-22.

Tarwater, Patrick M., and Clyde F. Martin. 2001. Effects of Population Density on the Spread of Disease. Complexity 6: 29-36. [CrossRef] 
Temsah, Mohamad-Hani, Fahad Al-Sohime, Nurah Alamro, Ayman Al-Eyadhy, Khalid Al-Hasan, Amr Jamal, Ibrahim Al-Maglouth, Fadi Aljamaan, Maha Al Amri, and Mazin Barry. 2020. The Psychological Impact of Covid-19 Pandemic on Health Care Workers in a Mers-Cov Endemic Country. Journal of Infection and Public Health 13: 877-82. [CrossRef]

Velavan, Thirumalaisamy P., and Christian G. Meyer. 2020. The Covid-19 Epidemic. Tropical Medicine E International Health 25: 278.

Verity, Robert, Lucy C. Okell, Ilaria Dorigatti, Peter Winskill, Charles Whittaker, Natsuko Imai, Gina Cuomo-Dannenburg, Hayley Thompson, Patrick G. T. Walker, and Han Fu. 2020. Estimates of the Severity of Coronavirus Disease 2019: A Model-Based Analysis. The Lancet Infectious Diseases 20: 669-77. [CrossRef]

Vindegaard, Nina, and Michael Eriksen Benros. 2020. Covid-19 Pandemic and Mental Health Consequences: Systematic Review of the Current Evidence. Brain, Behavior, and Immunity. Available online: https: //www.sciencedirect.com/journal/brain-behavior-and-immunity/special-issue/10T0PLVWMN7 (accessed on 31 August 2020).

Weatherall, David, Brian Greenwood, Heng Leng Chee, and Prawase Wasi. 2006. Science and Technology for Disease Control: Past, Present, and Future. Disease Control Priorities in Developing Countries 2: 119-38.

Whiting, David, and Nigel Unwin. 2009. Cities, Urbanization and Health. International Journal of Epidemiology 38: 1737-38. [CrossRef]

WHO. 2020. Who Coronavirus Disease (Covid-19) Dashboard. Last Accessed 16 July 2020. In Global Situation. Geneva: WHO.

Willman, Marnie, Darwyn Kobasa, and Jason Kindrachuk. 2019. A Comparative Analysis of Factors Influencing Two Outbreaks of Middle Eastern Respiratory Syndrome (Mers) in Saudi Arabia and South Korea. Viruses 11: 1119. [CrossRef] [PubMed]

World Bank. 2020. World Bank Country and Lending Groups. Washington: World Bank Data Help Desk.

Worldometer. 2020. Countries in the World by Population. In Data Based on the Latest United Nations Population Division Estimates. Available online: https://www.worldometers.info/ (accessed on 31 August 2020).

Wu, Joseph T., Kathy Leung, and Gabriel M. Leung. 2020. Nowcasting and Forecasting the Potential Domestic and International Spread of the 2019-Ncov Outbreak Originating in Wuhan, China: A Modelling Study. The Lancet 395: 689-97. [CrossRef]

Xie, Jingui, and Yongjian Zhu. 2020. Association between Ambient Temperature and Covid-19 Infection in 122 Cities from China. Science of the Total Environment 724: 138201. [CrossRef] [PubMed]

Zaki, Nazar, Hany Alashwal, and Sahar Ibrahim. 2020. Association of Hypertension, Diabetes, Stroke, Cancer, Kidney Disease, and High-Cholesterol with Covid-19 Disease Severity and Fatality: A Systematic Review. Diabetes E Metabolic Syndrome: Clinical Research \& Reviews 14: 1133-42. [CrossRef]

Zheng, Jun. 2020. Sars-Cov-2: An Emerging Coronavirus That Causes a Global Threat. International Journal of Biological Sciences 16: 1678. [CrossRef]

Zheng, Ruizhi, Yu Xu, Weiqing Wang, Guang Ning, and Yufang Bi. 2020. Spatial Transmission of Covid-19 Via Public and Private Transportation in China. Travel Medicine and Infectious Disease 34: 101626. [CrossRef]

Zhu, Lihua, Zhi-Gang She, Xu Cheng, Juan-Juan Qin, Xiao-Jing Zhang, Jingjing Cai, Fang Lei, Haitao Wang, Jing Xie, and Wenxin Wang. 2020. Association of Blood Glucose Control and Outcomes in Patients with Covid-19 and Pre-Existing Type 2 Diabetes. Cell Metabolism 31: 1068-77. [CrossRef]

(C) 2020 by the authors. Licensee MDPI, Basel, Switzerland. This article is an open access article distributed under the terms and conditions of the Creative Commons Attribution (CC BY) license (http://creativecommons.org/licenses/by/4.0/). 